\title{
Evaluating the effect of aquatic extraction of Cannabis sativa seed on spatial memory consolidation in rats
}

\author{
Saeedeh Ebrahimpour ${ }^{*}$, Maryam Tehranipour ${ }^{1}$, Morteza Behnam², Morteza Kafaee ${ }^{1}$ \\ From $1^{\text {st }}$ International Congress on Neurobiology and Clinical Psychopharmacology and European \\ Psychiatric Association Conference on Treatment Guidance \\ Thessaloniki, Greece. 19-22 November 2009
}

\section{Background}

The existence of an endocannabinoid system in the central nervous system that consists of $G$ protein-coupled CB1 cannabinoid receptors and endocannabinoids, including arachidonylethanolamide and 2-arachidonoylglycerol, has gained general acceptance. Recent reports suggest that this system may serve several physiological functions including learing and memory functions

\section{Materials and methods}

40 male wistar rats (3-4 month, 320-260 g) were completely divided into 4 experimental groups and control group. Cannabis sativa seed was extracted with Soxhlet apparatus. To test spatial memory, Morris water mazemaze ( 7 days, 4 trails) was used. Experimental groups with $50 \mathrm{mg} \cdot \mathrm{kg}^{-1}, 100 \mathrm{mg} \cdot \mathrm{kg}^{-1}, 150 \mathrm{mg} \cdot \mathrm{kg}^{-1}, 210 \mathrm{mg} \cdot \mathrm{kg}^{-1}$ were injected in the peritoneal (IP) orderly and after one hour of injection spatial memory was done.

\section{Results}

The result show that experimental groups $\left(50 \mathrm{mg} \cdot \mathrm{kg}^{-1}\right.$, $100 \mathrm{mg} \cdot \mathrm{kg}^{-1}, 150 \mathrm{mg} \cdot \mathrm{kg}^{-1}$ doses), for learning time have significant level deduction in the comparison of controlgroup ( $\mathrm{p}<0.05)$, but experimental group with $210 \mathrm{mg} \cdot \mathrm{kg}^{-1}$ dose has not significant level in the comparison of control group $(\mathrm{p}<0.05)$.

\section{Conclusions}

We demonstrate tetrahydrocannabinol can change brain function as learning and memory processes and probably was done with Depolarization-Induced Suppression of excitatory (DSE) mechanism in the CA1 area of Hippocamp that with neurotransmitter regulation cause to neuroplasticity.

\section{Acknowledgements}

We thank Dr Heravi and Mr Kazemi for money support and Azad University of Mashhad for prepare Lab for Test.

\section{Author details}

${ }^{1}$ Department of Biology, Faculty of Science, Islamic Azad University, Mashhad Branch, Mashhad, Iran. ${ }^{2}$ Department of Biology, Faculty of Science, Ferdowsi University of Mashhad, Mashhad, Iran.

\section{Published: 22 April 2010}

References

1. Lee Jonathan LC: Memory reconsolidation mediates the strengthening of memories by additional learning. Nature Neuroscience 2008, 11:1264-1266.

2. Kawamura Y, Fukaya M, Maejima T, Yoshida T, Miura E, Watanabe M, OhnoShosaku T, Kano M: The CB1 Cannabinoid Receptor Is the Major Cannabinoid Receptor at Excitatory Presynaptic Sites in the Hippocampus and Cerebellum. Neuroscience 2006, 26:2991-3001.

3. Kyari MZ: Extraction and Charachterization of seed oils. Int Agrophysics 2008, 22:139-142.

4. Varvel SA, Litchman AH: Evaluation of $\mathrm{CB} 1$ receptor knockout mice in the Morris water maze. Pharmacol Exp Ther 2002, 301:915-24.

doi:10.1186/1744-859X-9-S1-S139

Cite this article as: Ebrahimpour et al:: Evaluating the effect of aquatic extraction of Cannabis sativa seed on spatial memory consolidation in rats. Annals of General Psychiatry 2010 9(Suppl 1):S139. 